Marketing in Asia Group

\title{
Predicting Social Capital on Multidimensional Service Quality: A Facebook Perspective
}

\author{
Md. Alamgir Hossain \\ Department of Management, Hajee Mohammad Danesh Science and Technology \\ University, Bangladesh \\ Minho Kim \\ Department of International Trade, Chonbuk National University, South Korea
}

\begin{abstract}
With the real-time communications prevalent in Facebook, it has been emerged as an increasingly popular social media that facilitates the bridging and bonding of social capital. This study reviews the consequences of service qualities for social capital through multidimensional service quality and social capital theory. Desired information is collected using a structured questionnaire comprising items of Facebook outcome quality, environment quality, interaction quality, satisfaction, usage intention, bridging, and bonding social capital, and analysed by the structural equation modelling. Results confirm that outcome and environment quality have significant positive influence on users' satisfaction and usage intention. Meanwhile, bridging and bonding social capital are highly predicted by satisfaction and usage intention, leading to the conclusion that Facebook helps to build and maintain social capital by increasing satisfaction and usage intention. The findings provide valuable insights for practitioners to shape a more balanced job-social capital relationship by adjusting service quality dimensions.
\end{abstract}

Keywords: Social Capital Theory, Multidimensional Service Quality, Facebook, Continuous Usage Intention

Publication Details: Received 28 Aug 2019; Revised 29 July 2020; Accepted 10 Sep 2020 


\section{Introduction}

The growing popularity of Facebook sees it as an important part of citizens to develop and maintain social capital. Among the other social networking sites (hereinafter SNS), Facebook is an eye-catching one with its inclusive ease-of-use and hi-tech competency, serving to shape interactive communication (Ellison et al., 2007; Raza et al., 2016; Bano et al., 2019). It allows users to connect with their friends and family, to stay in touch with acquaintances, and to connect with new friends. People spend more time to extend and sustain relationships by providing online status, sharing photos, videos, giving thumb-ups, comments, and participating in entertainment activities with others (Ellison et al., 2014; Raza et al., 2016), and individual bonding social capital can be nurtured and cultivated in SNS (Williams, 2019). Owing the global popularity of Facebook SNS, it provides valuable reflections of typical social collaboration process and their impacts on society (Ellison et al., 2007; Ellison et al., 2014; Su \& Chan, 2017), shows important relations of multidimensional service quality theory for behavioural intention (Lu et al., 2009; Lien et al., 2017, Hossain \& Kim, 2020). In addition, rapid usage of SNS builds social bridging and bonding among users thereby leading to enrich psychological wellbeing (Bano et al., 2019), in particular to receive emotional, informational, esteem and network support (High \& Buehler, 2017).

The antecedents of Facebook usage intention and social capital is one of the main research themes in current literatures (Ellison et al., 2007; Valenzuela et al., 2009; Phua et al., 2017; Su \& Chan, 2017; Bano et al., 2019; Tobin et al., 2020). Social capital is the ability of individuals or groups to permission integrated resources in their social network (Bourdieu, 1986; Coleman, 1988) and is often divided into 'bridging' and 'bonding' (Williams, 2006). These social capital are significantly influenced by intensity of Facebook use (High \& Buehler, 2017), Facebook use intensity and Facebook-enabled communication tracks (Su \& Chan, 2017), intention to continuous use (Hossain \& Kim, 2020; Raza et al., 2016), uses and gratifications (Phua et al., 2017), Facebook affiliation maintenance behaviours (Ellison et al., 2014), and benefits of Facebook partners (Ellison et al., 2007). Four distinct types of social capital (e.g., offline participation, emotional support, horizon broadening and networking value) are predicted by greater Facebook responding and sources of capital (Tobin et al., 2020). Furthermore, another research theme of multidimensional service quality theory has attracted much attention to measure the continuous usage intention of SNS use (Hossain \& Kim, 2018; Zhang et al., 2016; Lu et al., 2009). Multidimensional service dimensions have been used by Hossain and Kim (2020) to responded SNS usage intention and users' satisfaction, Hossain and Kim (2018) to address Facebook users' satisfaction and word-of-mouth communication and Lien et al. (2017) to address the usage intention of WeChat. While the previous studies examined separately whether social capital is generated through Facebook usage, and continuance usage intention is generated through multidimensional service quality, the antecedents between social capital and multidimensional service quality in SNS research context remain undiscovered. 
In particular, incorporating the social capital theory and multidimensional service quality theory, we aim to examine the behavioural intention of Facebook users and to examine whether social capital (e.g., bridging and bonding social capital) is derived from the use of Facebook. In addition, the study wants to validate the relationship between these two important theories in the Facebook context. To do this, three specific types of Facebook service qualities (e.g., outcome quality, environment quality and interaction quality) are identified and examined their impacts on behavioural intentions (e.g., continuous usage intention and users' satisfaction). Since, SNS user's satisfaction, usage intention, WOM attitude are already validated by interaction, environment and outcome quality (Lien et al., 2017; Hossain \& Kim, 2018 \& 2020), this study applies the same approach. Furthermore, we explore social capital based on the behavioural intentions of Facebook users in line with the approach of Ellison et al. (2014), Phua et al. (2017) and Hossain and Kim (2020).

The contribution of the study is threefold. Frist, the study incorporated social capital theory and multidimensional service quality theory into the Facebook SNS, which would bring additional domains into SNS research context. To the best of our knowledge no previous studies have conducted in this SNS context that incorporates these two theories. Second, this study considers behavioural intention as an independent and dependent variable in the model, which would explain the most and important service quality in order to predict the behavioural intentions and social support received by users. Third, the study offers a set of suggestions that practitioners can use to measure their SNS service quality, to identify opportunities for improvement, and to channel their knowledge and resources to improve social capital.

The following section shows the literature review. The next section addresses the methodology used in our study. Results and discussions with managerial implementation are presented in sections 4 and 5, respectively. The last section draws a conclusion and future research guidelines.

\section{Literature Review}

\section{Theoretical Ground}

Bourdieu (1986) defines social capital as the aggregate of unique latent resources related to a sustainable network of more or less recognized relationships of acquaintance and recognition. It is the resources that can be retrieved, accrued and mobilized through a social network and relationships (Coleman, 1988), especially in the context of communication media (Ellison et al., 2014). These resources may include mutual trust, emotional support, and entree to social data (Ellison et al., 2014b). Putnam (2000) addresses the social capital in two main dimensions; bridging and bonding social capital. Similarly, Bano et al. (2019) argue that social bridging and bonding are fundamental dimensions of social capital in their study of WhatsApp use and the psychological wellbeing of students. There are several studies used social capital theory to explore SNS relationships (Ellison et al., 2007; Raza et al., 2016; Su 
\& Chan, 2017; High \& Buehler, 2017). Williams (2006) develops a scale of social capital based on Putnam's (2000) proposals, and Ellison et al. (2014) adapts this scale to Facebook. The current study considers Facebook-related bridging and bonding of social capital.

Recently, Hossain and Kim (2018 \& 2020) utilize the hierarchical and multidimensional model by Brady and Cronin (2001), in particular the dimensions of interaction, environment and outcome service quality to investigate the SNS user's usage intention, satisfaction, WOM communication. Lien et al. (2017) utilize the same to investigate the influence of service quality on WeChat users' satisfaction. They also examine the influence of satisfaction and stickiness on usages intentions. Likewise, Brady and Cronin (2001) model has been used by other researchers (Lu et al., 2009; Zhao et al., 2012) in a similar context. Given the importance of reliability and validity of these studies, the current study adopts the multi-dimensional service quality scale used by Hossain and Kim (2018 \& 2020) and Lien et al. (2017) to measure the behavioural intentions of Facebook users.

From the empirical analysis, the service quality and social capital of Facebook has shifted from general service quality and use intention to what people have done with particular technical functions in recent years. This study endures to examine the association between Facebook service qualities and social capital by examining how the behavioural intentions of Facebook users are shaped by multidimensional service quality and how social capital is achieved through behavioural intentions. We, therefore, proposes the following research model presented in Figure 1. It also literally introduces the hypothetical paths of the research model.

Figure 1: Proposed Research Model

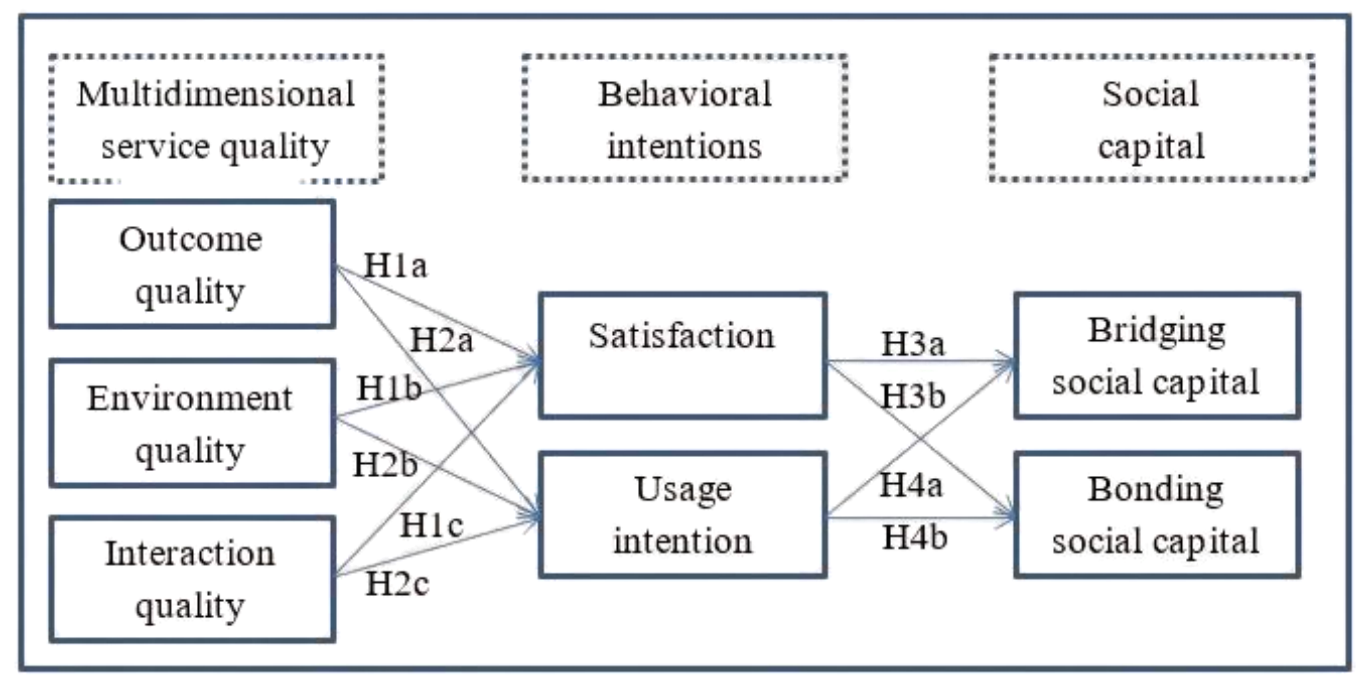




\section{Hypotheses Development}

Service quality is an important driver in the overall service experience and benefits of the service being evaluated by the consumers. Due to the subjectivity and the participation of the customers in the service system, the concept of service quality is quite difficult to define. Initially, two dimensional models of service quality were perceived by Gronroos (1984) and two main models of service quality comprising SERVQUAL were proposed by Parasuraman et al. (1985). Although SERVQUAL is widely used in the service industry, it has been criticized by many other scholars for the use of difference scores and interpretations of expectations (Dyke et al., 1997). Cronin and Taylor (1992) have proposed SERVPERF to assess the service quality and outcomes which indicate that the use of performance scores produces better validity and reliability. Most significantly, Brady and Cronin (2001) conceptualized a multidimensional and hierarchical service quality theory for measuring service quality that includes three components: outcome quality, environment quality, and interaction quality. Their service quality model focuses on the following three main concepts of service quality: firstly, it defines the perception of service quality, secondly, in what way service quality is made, and thirdly, how imperative it is, where service experience takes place.

In recent years, significant numbers of researchers have integrated multidimensional service quality concept into the SNS context. Hossain and Kim (2018 \& 2020) and Lien et al. (2017) integrates multidimensional service theory in their SNS study and find this theory fits well. They argue that among the three components, outcome quality and environment quality measure user's satisfaction and usage intention significantly. The outcome of a service refers to what the customer gets from the service. Tangible evidence, punctuality of service delivery and intangible valence are the sub dimensions of outcome quality. That are straight connected to the fulfilment of user's desire and signals of feeling about the experience. Lien et al. (2017) notes that SNS user satisfaction is highly depend on outcome quality. However, Zhao et al. (2012) finds that clients pay more care to the outcome quality when assessing aggregate satisfaction. Table 1 summarizes the existing literature on service quality and social capital theory of SNS, and presents the objective of the studies, the theories used, and the major results as well. 
Table 1: Existing Studies on Service Quality and Social Capital Theory of SNS

\begin{tabular}{|c|c|c|c|}
\hline Research & Purpose/ objective & $\begin{array}{l}\text { Theory/ } \\
\text { model used }\end{array}$ & Hypotheses/results \\
\hline $\begin{array}{l}\text { Hossain and } \\
\text { Kim (2020) }\end{array}$ & $\begin{array}{l}\text { Examine the user's } \\
\text { perceptions of the } \\
\text { service quality of } \\
\text { SNSs, contributing to } \\
\text { customer satisfaction } \\
\text { and usage intention } \\
\text { leading to social } \\
\text { commerce intention. }\end{array}$ & $\begin{array}{l}\text { Multi- } \\
\text { dimensional } \\
\text { service } \\
\text { quality } \\
\text { theory. }\end{array}$ & $\begin{array}{l}\text { Outcome quality } \rightarrow \text { satisfaction* } \\
\text { Interacting quality } \rightarrow \text { satisfaction } \\
\text { Environment quality } \rightarrow \text { satisfaction* } \\
\text { Outcome quality } \rightarrow \text { usage intention* } \\
\text { Interacting quality } \rightarrow \text { usage intention* } \\
\text { Environment quality } \rightarrow \text { usage intention }\end{array}$ \\
\hline $\begin{array}{l}\text { Lien, Cao, } \\
\text { and Zhou } \\
\text { (2017) }\end{array}$ & $\begin{array}{l}\text { Observe the impact of } \\
\text { service quality on } \\
\text { WeChat users' } \\
\text { satisfaction and assess } \\
\text { the influence of } \\
\text { satisfaction and } \\
\text { stickiness on usage } \\
\text { intentions. }\end{array}$ & $\begin{array}{l}\text { Multi- } \\
\text { dimensional } \\
\text { service } \\
\text { quality } \\
\text { theory. }\end{array}$ & $\begin{array}{l}\text { Interacting quality } \rightarrow \text { satisfaction } \\
\text { Environment quality } \rightarrow \text { satisfaction* } \\
\text { Outcome quality } \rightarrow \text { satisfaction* } \\
\text { Satisfaction } \rightarrow \text { usage intention* } \\
\text { Satisfaction } \rightarrow \text { stickiness* }\end{array}$ \\
\hline $\begin{array}{l}\text { Phua, Jin, } \\
\text { and Kim } \\
\text { (2017) }\end{array}$ & $\begin{array}{l}\text { Examine the users of } \\
\text { four SNSs, and their } \\
\text { influence on online } \\
\text { bridging and bonding } \\
\text { social capital. }\end{array}$ & $\begin{array}{l}\text { Uses and } \\
\text { gratification, } \\
\text { Social } \\
\text { capital } \\
\text { theory. }\end{array}$ & $\begin{array}{l}\text { This study examined frequent users of } \\
\text { four major SNS platforms (Facebook, } \\
\text { Twitter, Instagram, and Snapchat), } \\
\text { bridging and bonding social capital } \\
\text { derived from each SNS. }\end{array}$ \\
\hline $\begin{array}{l}\text { Su and Chan } \\
\text { (2017) }\end{array}$ & $\begin{array}{l}\text { It examines whether } \\
\text { perceived content } \\
\text { desirability and } \\
\text { Facebook-enabled } \\
\text { communication } \\
\text { practices matter for } \\
\text { furthering social } \\
\text { capital via Facebook. }\end{array}$ & $\begin{array}{l}\text { Social } \\
\text { capital. }\end{array}$ & $\begin{array}{l}\text { Perceived desirability of Facebook } \\
\text { content } \rightarrow \text { Facebook-enabled } \\
\text { communication practices* } \\
\text { Perceived desirability of Facebook } \\
\text { content } \rightarrow \text { Bridging social capital* } \\
\text { Perceived desirability of Facebook } \\
\text { content } \rightarrow \text { bonding social capital* } \\
\text { Facebook-enabled communication } \\
\text { practice } \rightarrow \text { bonding social capital* }\end{array}$ \\
\hline $\begin{array}{l}\text { Raza, Qazi, } \\
\text { and Umer } \\
(2016)\end{array}$ & $\begin{array}{l}\text { This study examines } \\
\text { the influence of } \\
\text { Facebook usage on } \\
\text { building social capital. }\end{array}$ & $\begin{array}{l}\text { Modified } \\
\text { framework } \\
\text { of } \\
\text { technology } \\
\text { acceptance } \\
\text { model. }\end{array}$ & $\begin{array}{l}\text { Perceived usefulness } \rightarrow \text { usage intention* } \\
\text { Perceived ease of use } \rightarrow \text { usage intention* } \\
\text { Perceived playfulness } \rightarrow \text { usage intention* } \\
\text { Social self-efficacy } \rightarrow \text { usage intention* } \\
\text { Facebook intensity } \rightarrow \text { usage intention* } \\
\text { Usage intention } \rightarrow \text { bonding social capital* } \\
\text { Usage intention } \rightarrow \text { bridging social capital* }\end{array}$ \\
\hline $\begin{array}{l}\text { Zhang, Li, } \\
\text { Wu, and Li } \\
\text { (2016) }\end{array}$ & $\begin{array}{l}\text { Examined the effects } \\
\text { of direct and indirect } \\
\text { network externalities } \\
\text { on users' perceived } \\
\text { values (including } \\
\text { social value, } \\
\text { information value, } \\
\text { emotional value, and } \\
\text { hedonic value) and }\end{array}$ & $\begin{array}{l}\text { Structural } \\
\text { equation } \\
\text { modeling } \\
\text { (SEM). }\end{array}$ & $\begin{array}{l}\text { Social interaction ties mediate the effect } \\
\text { of network externalities on the four types } \\
\text { of perceived values. Meanwhile, among } \\
\text { the four types of perceived values, only } \\
\text { social value and hedonic value influence } \\
\text { continuance intention. }\end{array}$ \\
\hline
\end{tabular}


continuance intention.

$\begin{array}{llll}\begin{array}{l}\text { Ellison, } \\ \text { Vitak, Gray, } \\ \text { and Lampe } \\ (2014)\end{array} & \begin{array}{l}\text { Explores the } \\ \text { relationship between } \\ \text { perceived bridging } \\ \text { social capital and } \\ \text { specific Facebook- } \\ \text { enabled } \\ \text { communication } \\ \text { behaviors. }\end{array} & \begin{array}{l}\text { Social } \\ \text { capital and } \\ \text { relationship } \\ \text { maintenance } \\ \text { theory. }\end{array} & \begin{array}{l}\text { Drawing upon scholarship on social } \\ \text { capital and relationship maintenance, this } \\ \text { study discusses the role of social } \\ \text { grooming and attention-signaling } \\ \text { activities in shaping perceived access to } \\ \text { resources in one's network as measured } \\ \text { by bridging social capital }\end{array} \\ \begin{array}{llll}\text { Zhao, Lu, } \\ \text { Zhang, and } \\ \text { Chau (2012) } \\ \text { of service quality and } \\ \text { justice on customer } \\ \text { satisfaction, which, in } \\ \text { turn, affects } \\ \text { continuance intention } \\ \text { of mobile services. }\end{array} & \begin{array}{l}\text { Service } \\ \text { quality, } \\ \text { justice and } \\ \text { customer } \\ \text { satisfaction } \\ \text { were } \\ \text { measured by } \\ \text { multiple } \\ \text { dimensions } \\ \text { theory. }\end{array} & \begin{array}{l}\text { Interacting quality } \rightarrow \text { transaction-specific } \\ \text { satisfaction* } \\ \text { Interacting quality } \rightarrow \text { cumulative } \\ \text { satisfaction* }\end{array} & \begin{array}{l}\text { Environment quality } \rightarrow \text { cumulative } \\ \text { satisfaction* } \\ \text { Outcome quality } \rightarrow \text { cumulative } \\ \text { satisfaction* } \\ \text { Distributive justice } \rightarrow \text { cumulative } \\ \text { satisfaction* } \\ \text { Transaction-specific } \\ \text { satisfaction } \rightarrow \text { continuance intention* } \\ \text { Cumulative satisfaction } \rightarrow \text { continuance } \\ \text { intention* }\end{array} \\ & & & \end{array}$

Note: *Significant

Lu et al. (2009) defines the environment quality of mobile services in relation to the essential requirements (e.g. service delivery context, interface design, equipment quality) for the use of the services. Without a good environment it would be difficult for customers to attain their purpose. Researchers speculate that the excellence of interface design and the stable mobile telecommunications connection mean greater consumers perception of environment quality that influences their behavioural attitude. In this regard, Kuo et al. (2009) addresses system reliability, visual design, navigation and connection qualities are vital service quality dimensions that affect client satisfaction and value. SNS user satisfaction and WOM communication have been well examined by environment service quality (Hossain \& Kim, 2018). The buyer-seller interaction of the service delivery process is called interaction quality, which is inevitably important for long-run relationships. Interaction quality echoes the quality of a client's interaction with the retailer in the service transfer process ( $\mathrm{Lu}$ et al., 2009). Hossain and Kim (2020) argue that there is a significant positive association between interaction service quality and SNS users' satisfaction and usage intention. According to Zhao et al. (2012) the interaction service quality has an important positive impact on consumer satisfaction and usage intention as well. Therefore, basing on the aforementioned discussions, we assume that there is a significant positive relationship between service quality dimensions (interaction, environment, and outcome) and Facebook users' satisfaction and continuous usage intention. Accordingly, we propose the following hypotheses:

H1 Facebook users' satisfaction is positively influenced by H1a-outcome quality, H1b-envirnment quality, and H1c-interaction quality. 
H2 Facebooks users' usage intention is positively influenced by H2a-outcome quality, H2b-envirnment quality, and $\mathrm{H} 2 \mathrm{c}$-interaction quality.

Furthermore, recent study has established that SNS is an important platform for people to accrue and activate their virtual social capital. Social capital can be called human or intellectual capital. The social capital can be formed by social relationships and expectations of future resources (Ellison et al., 2014). Bourdieu (1986) and Coleman (1988) have considered social capital theory as the capability of persons or groups to access resources implanted in their social network. Individuals are interconnected in their social networks, which are built by investing in relationships, and these investments can turn into other resources. Social capital can be parted into 'bridging' and 'bonding' social capital (Putnam, 2000; Williams, 2006). According to Ellison et al. (2014), a comparative weaker tie (e.g., friend of friend) that connects unlike clusters in a network, often referred as "bridging social capital". And stronger ties (e.g., trust, support) typically offer access to the substance forms of capital called "bonding social capital". Facebook SNS has both stronger and weaker ties (Bakshy et al., 2012).

The association between social capital and the use of Facebook has been studied by several researchers, who suggest that excessive use of SNS will increase social capital enormously. Bano et al. (2019) note that social capital (e.g., bridging, bonding) is significantly influenced by the use of WhatsApp, which is likely to improve student's psychological wellbeing. Valenzuela et al. (2009) observe the positive association between student life satisfaction and the use of Facebook. The technical functions, for example like or comments allow users to receive and respond with emotional and social supports on Facebook at a lower charge what ultimately results in the greater level of social capital (Ellison et al., 2014; Ellison et al., 2014b). Su and Chan (2017) posit that the use of technical sorts in turn touches bridging and bonding social capital via Facebook. According to Raza et al. (2016), continuance usage intention of Facebook is the foundation of bridging and bonding social capital. Phua and Jin (2011) note that there is a positive association between SNS use and bridging and bonding social capital. These association potentially affects emotional, esteem, network and informational support (High \& Buehler, 2017). From the Facebook study, Ellison et al. (2007) find link between Facebook use and social capital. Additionally, Ellison et al. (2014) argue that having the Facebook relationship, comprising displaying sympathy and cheers of others, has led to social bridging and bonding. Therefore, the following hypotheses have proposed:

H3 Facebook users' satisfaction has a positive influence on (H3a-bridging social capital and H3b-bonding social capital).

H4 Facebook users' continuance usage intention has a positive influence on (H4abridging social capital and H4b-bonding social capital). 


\section{Methodology}

\section{Data}

We collected data by using a self-administered structured questionnaire via online survey, where measurement instrument were inspected by educational and professional researchers. A pilot study with 35 participants has been made in order to reassure the consistency, order, and relevancy of the questionnaire design. After the modification and changes, 35 measurement items were kept, while single item was deleted from each construct to achieve model fit. A five-point Likert scale ranges from strongly disagree (1) to strongly agree (5) were used. A random sampling technique was used and the final sample size was 307. As there are several existing literatures (e.g., Lien et al., 2017; Bano et al., 2019) consists around the similar sample size of current study representing sample size is sufficient and representative. The questionnaire link was provided to the participants at random with instructions included on the first page. It was also acknowledged that all information provided would be kept confidential.

Participants were asked to provide some specific demographic characteristics for descriptive purposes. Approximately 55\% respondents are male and 45\% are female. More than $70 \%$ of participants are between 20 and 30 years old, 29\% are private employees, $16 \%$ are government employees, and $42 \%$ are students. Almost $95 \%$ of the respondents use Facebook for more than 3 years and spend more than 20 minutes a day.

\section{Measures}

All the measurement items are adopted and modified from the earlier research to ensure the validity of theses constructs and to fit the context with SNS usage. The measurement items of bridging social capital and bonding social capital are from $\mathrm{Su}$ and Chan (2017). The measures of outcome quality, environment quality and interaction quality are from Lien et al. (2017) and Lu et al. (2009). User satisfaction and usage intention are modified from Zhang et al. (2016). Measurement items with their respective standardized estimates, and construct wise model fit indices are presented in Table 2.

\section{Method Bias Test}

The Common Method Variance (CMV) is examined by Harman's single factor test, which is recommended by Podsakoff et al. (2003). The issue of CMV arises if every item come in a single construction or if the first construction accounts for most of the variance in the data. The first factor that was extracted non-rotational factor analysis represents only $40 \%$ of the overall variance and several factors whose eigenvalues are more than one, representing CMV is not a critical issue for this study. 
Table 2: Measurement Instruments

\begin{tabular}{|c|c|c|c|c|}
\hline Construct and Items & Indicator & $\begin{array}{l}\text { Std. factor } \\
\text { loadings }\end{array}$ & $\mathbf{P}$ & Reference \\
\hline Bridging social capital $(\mathrm{GFI}=0.970, \mathrm{CFI}=0.967$, and $\mathrm{NFI}=964)$ & & & & $\begin{array}{l}\text { Su and Chan } \\
\text { (2017) }\end{array}$ \\
\hline By using Facebook, I feel I'm a part of the world. & $\mathrm{BRC} 1$ & 0.672 & $* * *$ & \\
\hline Facebook creates social awareness. & $\mathrm{BRC} 2$ & 0.790 & $* * *$ & \\
\hline Facebook is helpful for social networking. & $\mathrm{BRC} 4$ & 0.791 & $* * *$ & \\
\hline Facebook makes me feel like a part of big community. & BRC5 & 0.744 & & \\
\hline Bonding social capital $(\mathrm{GFI}=0.997, \mathrm{CFI}=0.997$, and $\mathrm{NFI}=0.994)$ & & & & $\begin{array}{l}\text { Su and Chan } \\
\text { (2017) }\end{array}$ \\
\hline I get inspired from Facebook friends. & BOC1 & 0.610 & $* * *$ & \\
\hline I feel a sense of belongingness with my favorite friends. & BOC2 & 0.793 & & \\
\hline Facebook is helpful for raising voice for 'Justice'. & BOC3 & 0.622 & $* * *$ & \\
\hline $\begin{array}{l}\text { There are several Facebook friends I trust to help solve my } \\
\text { problems. }\end{array}$ & BOC4 & 0.816 & $* * *$ & \\
\hline Satisfaction $(\mathrm{GFI}=0.995, \mathrm{CFI}=0.998$, and NFI=944) & & & & $\begin{array}{l}\text { Zhang et al. } \\
\text { (2016) }\end{array}$ \\
\hline I feel satisfied with using Facebook. & SAT1 & 0.824 & $* * *$ & \\
\hline I feel pleasant with using Facebook. & SAT2 & 0.874 & & \\
\hline I feel enjoyment using Facebook. & SAT3 & 0.730 & $* * *$ & \\
\hline Facebook has met my expectations. & SAT4 & 0.659 & $* * *$ & \\
\hline Usage Intention $(\mathrm{GFI}=0.983, \mathrm{CFI}=0.980$, and NFI $=976)$ & & & & $\begin{array}{l}\text { Zhang et al. } \\
\text { (2016) }\end{array}$ \\
\hline I will use Facebook in future. & INT1 & 0.766 & $* * *$ & \\
\hline I would use Facebook more than any other networks. & INT3 & 0.668 & & \\
\hline I would visit Facebook as often as I can. & INT4 & 0.638 & $* * *$ & \\
\hline I usually open Facebook when I am in online. & INT5 & 0.791 & $* * *$ & \\
\hline Outcome Quality (GFI=0.978, CFI=0.973, and NFI=968) & & & & $\begin{array}{l}\text { Lien et al. (2017); } \\
\text { Lu et al. (2009) }\end{array}$ \\
\hline I can save time and effort by FB communication. & OQ2 & 0.755 & $* * *$ & \\
\hline Facebook delivers the information very quickly. & OQ3 & 0.767 & $* * *$ & \\
\hline Facebook provides important information. & OQ4 & 0.762 & & \\
\hline I feel good about what Facebook provides to its users. & OQ5 & 0.606 & $* * *$ & \\
\hline Environment Quality (GFI=0.994, CFI=0.993, and NFI=990) & & & & $\begin{array}{l}\text { Lien et al. (2017); } \\
\text { Lu et al. (2009) }\end{array}$ \\
\hline Facebook display is easy to use. & EQ1 & 0.741 & $* * *$ & \\
\hline Facebook provides useful ‘emotional expression' icons. & EQ3 & 0.752 & $* * *$ & \\
\hline $\begin{array}{l}\text { Facebook provides useful supporting tools (e.g. photo, message } \\
\text { sharing). }\end{array}$ & EQ4 & 0.707 & & \\
\hline I would say Facebook interface design is creative. & EQ5 & 0.633 & $* * *$ & \\
\hline Interaction Quality (GFI=0.992, CFI=0.992, and NFI=987) & & & & $\begin{array}{l}\text { Lien et al. (2017); } \\
\text { Lu et al. (2009) }\end{array}$ \\
\hline Facebook authority is very friendly. & IQ2 & 0.696 & $* * *$ & \\
\hline Facebook authority is willing to solve my problem. & IQ3 & 0.808 & & \\
\hline Facebook is able to solve my questions thoroughly. & IQ4 & 0.768 & $* * *$ & \\
\hline Overall, Facebook interaction/chatting quality is good. & IQ5 & 0.605 & $* * *$ & \\
\hline
\end{tabular}

Note: $* * *$ significant at $\mathrm{p}<0.001$. 


\section{Results and Analysis}

For data analysis and hypothesis testing we applies structural equation modelling (hereinafter SEM). Particularly, we use AMOS-24 in order to obtain actual valuation of the measurement model and structural model. The SEM model authenticates the reliability and validity of the measurement model and aids to clarify the theoretical relationship between construct. Likewise, this technique also assesses some important model fit indices that confirm its additional power. Therefore, it can be noted that the research methodology used in the current study is sufficiently justified (Anderson \& Gerbing, 1988).

\section{Measurement Model}

We evaluate the reliability and validity of the measurement model before testing hypothetical relationships. The adequacy of measurement model is evaluated on the basis of critical conditions of convergent validity, internal consistency, discriminant validity, and multicollinearity issues. The convergent validity of the scales can be verified by two different criteria suggested by Hair et al. (2010). First, all standardized factor loads must surpass 0.70. Second, average variance extracted (AVE) of every construct should surpass 0.50 . It is revealed that almost all items loaded higher than 0.70 on their respective constructs as shown in Table 2. All AVE values range from 0.503 to 0.602 as shown in Table 3 , the results prove the convergent validity criteria.

Table 3 also shows composite reliability (CR) and Cronbach's alpha which are considered to evaluate the internal consistency, and the values are all greater than 0.70, which represents a good reliability of the scale (Hair et al., 2010). In addition, discriminant validity is examined by the following criteria. Firstly, the cross-factor loadings have shown that the loadings of each measurement item on the latent variable are larger than its loading on other constructs. Secondly, square root of AVE of a construct should larger than its correlations value with other constructs. It is revealed that these two conditions for discriminant validity are met. The model has good reliability and validity, therefore can be declared. Multicollinearity among the explanatory variables is judged using the variance inflation factor (VIF), and the values in Table 3 ranging from 1.26-2.58 being below than the threshold of 10 representing the acceptable level (Hair et al., 2010). Tolerance values in Table 3 range from 0.38 to 0.79 , representing the additional power of the model.

Table 3 demonstrations eight commonly used model fit indices to measure the overall goodness of fit of the measurement model. Results show that all the measurements meet their respective cut-off criteria. All model fit indices indicate a good model fit (Browne \& Cudeck, 1993; Doll et al., 1994; Hair et al., 2010). 
Table 3: Validity and Reliability Statistics

\begin{tabular}{|c|c|c|c|c|c|c|c|}
\hline Constructs & Mean & $\begin{array}{l}\text { Standard } \\
\text { deviation }\end{array}$ & $\begin{array}{c}\text { Average } \\
\text { variance } \\
\text { extracted } \\
\text { (AVE) }\end{array}$ & $\begin{array}{l}\text { Composite } \\
\text { reliability } \\
\text { (CR) }\end{array}$ & $\begin{array}{l}\text { Cronbach's } \\
\text { alpha }\end{array}$ & VIF & Tolerance \\
\hline Satisfaction & 3.71 & 0.75 & 0.602 & 0.857 & 0.845 & 2.58 & 0.38 \\
\hline Usage intention & 3.85 & 0.76 & 0.516 & 0.809 & 0.813 & 2.31 & 0.43 \\
\hline Outcome quality & 3.62 & 0.74 & 0.525 & 0.815 & 0.807 & 2.20 & 0.45 \\
\hline Environment quality & 3.89 & 0.76 & 0.503 & 0.802 & 0.791 & 1.58 & 0.63 \\
\hline Interaction quality & 3.33 & 0.77 & 0.523 & 0.816 & 0.807 & 1.26 & 0.79 \\
\hline Bridging social capital & 3.85 & 0.78 & 0.563 & 0.837 & 0.833 & & \\
\hline Bonding social capital & 3.70 & 0.73 & 0.513 & 0.805 & 0.785 & & \\
\hline \multicolumn{3}{|c|}{ Model fit indices } & btained value & \multicolumn{2}{|c|}{ Suggested value } & \multicolumn{2}{|c|}{ References } \\
\hline \multicolumn{3}{|c|}{$\begin{array}{l}\text { The ratio of chi-square to degrees of } \\
\text { freedom }\left(\mathrm{x}^{2} / \text { d.f. }\right)\end{array}$} & 1.589 & \multicolumn{2}{|c|}{$<3$} & \multicolumn{2}{|c|}{ Hair et al. (2010) } \\
\hline \multicolumn{3}{|c|}{ Goodness of fit index (GFI) } & 0.90 & \multicolumn{2}{|c|}{$>0.90$} & \multicolumn{2}{|c|}{ Hair et al. (2010) } \\
\hline \multicolumn{3}{|c|}{ Average GFI } & 0.88 & \multicolumn{2}{|c|}{$\geq 0.80$} & \multicolumn{2}{|c|}{ Doll et al. (1994) } \\
\hline \multicolumn{3}{|c|}{ Comparative fit index (CFI) } & 0.96 & \multicolumn{2}{|c|}{$\geq 0.90$} & \multicolumn{2}{|c|}{ Doll et al. (1994) } \\
\hline \multicolumn{3}{|c|}{ Normalized fit index (NFI) } & 0.91 & \multicolumn{2}{|c|}{$\geq 0.90$} & \multicolumn{2}{|c|}{ Hair et al. (2010) } \\
\hline \multicolumn{3}{|c|}{ Incremental fit index (IFI) } & 0.97 & \multicolumn{2}{|c|}{$\geq 0.90$} & \multicolumn{2}{|c|}{ Hair et al. (2010) } \\
\hline \multicolumn{3}{|c|}{ Tucker-Lewis index (TLI) } & 0.96 & \multicolumn{2}{|c|}{$\geq 0.90$} & \multicolumn{2}{|c|}{ Hair et al. (2010) } \\
\hline \multicolumn{3}{|c|}{$\begin{array}{l}\text { Root mean square error of } \\
\text { approximation (RMSEA) }\end{array}$} & 0.04 & \multicolumn{2}{|c|}{$\leq 0.05$} & \multicolumn{2}{|c|}{$\begin{array}{c}\text { Browne and Cudeck } \\
\text { (1993) }\end{array}$} \\
\hline
\end{tabular}

\section{Structural Model Assessment}

The estimated SEM equations are as follows:

$S A T=\{0.526(O Q)+0.275(E Q)+0.045(I Q)\}$

$I N T=\{0.444(O Q)+0.330(E Q)+0.032(I Q)\}$

$B R C=[0.301\{0.526(O Q)+0.275(E Q)+0.045(I Q)\}+0.394\{0.444(O Q)+0.330(E Q)$ $+0.032(I Q)\}]$

$B O C=[0.441\{0.526(O Q)+0.275(E Q)+0.045(I Q)\}+0.239\{0.444(O Q)+0.330(E Q)$ $+0.032(I Q)\}]$

where, SAT $=$ Satisfaction, INT $=$ Usage intention, $\mathrm{BRC}=$ Bridging social capital, $\mathrm{BOC}=$ Bonding social capital, $\mathrm{OQ}=$ Outcome quality, $\mathrm{EQ}=$ Environment quality, $\mathrm{IQ}=$ Interaction quality.

Based on the satisfaction of reliability and validity of the measurement model, this study evaluates the parameters of the structural model, and standardized solutions produced using AMOS-24. The model is examined by checking the path coefficients ( $\beta$ weights) representing the quality of relationship among the constructs. The hypothetical path coefficient and significance of each hypothesis are examined. As shown in Table 4, the structural model accounts for $52 \%$ of the variance in user 
satisfaction, $47 \%$ of the variance in usage intention, $36 \%$ of the variance in bridging social capital, and $36 \%$ of the variance in bonding social capital. Therefore, the proposed model explains $(36+36)=72 \%$ of the variance of social capital.

Table 4 also shows the summary of hypotheses results. Among the ten hypotheses eight are supported $(\mathrm{p}<0.001)$. The satisfaction of Facebook users is highly influenced by outcome quality $(\beta=0.526, p<0.001)$ and environment quality $(\beta=0.275, p<0.001)$. Similarly, the intention of Facebook usage is highly predicted by outcome quality $(\beta=0.444, \quad p<0.001)$ and environment quality $(\beta=0.330, \quad p<0.001)$, therefore, hypotheses $\mathrm{H} 1 \mathrm{a}, \mathrm{H} 1 \mathrm{~b}, \mathrm{H} 2 \mathrm{a}$ and $\mathrm{H} 2 \mathrm{~b}$ are supported. In addition, bridging and bonding social capital are positively influenced by satisfaction and usage intention. Thus, $\mathrm{H} 3 \mathrm{a}$ $(\beta=0.301, \mathrm{p}<0.001), \mathrm{H} 3 \mathrm{~b}(\beta=0.441, \mathrm{p}<0.001), \mathrm{H} 4 \mathrm{a}(\beta=0.394, \mathrm{p}<0.001)$, and $\mathrm{H} 4 \mathrm{~b}$ $(\beta=0.239, \mathrm{p}<0.001)$ are supported. However, explanatory variable interaction quality does not show a significant effect on satisfaction or usage intention, thus $\mathrm{H} 1 \mathrm{c}$ and $\mathrm{H} 2 \mathrm{c}$ are not supported.

Table 4: Results of Hypotheses

\begin{tabular}{ccccc}
\hline Hypotheses & Standardized estimate & S.E. & P & Conclusion \\
\hline H1a & 0.526 & 0.049 & $* * *$ & Supported \\
H1b & 0.275 & 0.044 & $* * *$ & Supported \\
H1c & 0.045 & 0.043 & 0.306 & Not-supported \\
H2a & 0.444 & 0.053 & $* * *$ & Supported \\
H2b & 0.330 & 0.048 & $* * *$ & Supported \\
H2c & 0.032 & 0.046 & 0.497 & Not-supported \\
H3a & 0.301 & 0.054 & $* * *$ & Supported \\
H3b & 0.441 & 0.050 & $* * *$ & Supported \\
H4a & 0.394 & 0.053 & $* * *$ & Supported \\
H4b & 0.239 & 0.050 & $* * *$ & Supported \\
\hline Variance explained: & R squared & & & \\
Satisfaction & $52 \%$ & & & \\
Usage intention & $47 \%$ & & & \\
Bridging social capital & $36 \%$ & & & \\
Bonding social capital & $36 \%$ & & & \\
Note: *** significant at $\mathrm{p}<0.001$. & & &
\end{tabular}




\section{Discussion and Implications}

The purpose of this study is to understand how social capital can be predicted under the lens of multidimensional service theory, along with the integrating the behavioural approach of Facebook users. This study hypothesizes and demonstrates the impact of multidimensional service quality theory on behavioural intentions. In addition, the results also validate the impact of behavioural intentions on social capital. The results show that the multidimensional service quality dimensions; outcome quality and environment quality have a significant positive impact on the user satisfaction and usage intention of Facebook. These associations support the hypotheses H1a, H1b, H2a, and H2b that correspond to previous studies (Lien et al., 2017; Hossain \& Kim, 2020). Therefore, it can be postulated that content quality, service punctuality, easy navigation, interface design, connection quality, and stability are the fundamental attributes that relate to the outcome and environment quality, and significantly affect the satisfaction and usage intention of Facebook. Accordingly, these ultimately affect the development of social capital.

It is somewhat surprising that interaction quality does not have a significant impact on satisfaction and usage intention. Of the ten paths only two paths (hypotheses H1c and $\mathrm{H} 2 \mathrm{c}$ ) are insignificant, which are not consistent with the results of the study by Zhao et al. (2012). This might happen because of excessive emphasis on outcome qualitythe actual services that user obtains from the service provider, and also on environment quality- related to the interface design and service delivery. Another potential reason could be that respondents might not rely on Facebook friend's help when they needed it, rather they immediately get help from their surrounding friends and family through the use of Facebook. Therefore, the interaction quality is not a big issue that affecting behavioural intentions in this study.

The path connecting user's satisfaction with bridging and bonding social capital is positive and significant $(\beta=0.301, \mathrm{p}<0.001)$ and $(\beta=0.441, \mathrm{p}<0.001)$, hence keeping the hypotheses $\mathrm{H} 3 \mathrm{a}$ and $\mathrm{H} 3 \mathrm{~b}$. These results support the findings of earlier studies (Ellison et al., 2014; Su \& Chan, 2017). According to Ellison et al. (2014) Facebook enables users to receive and reciprocate emotional social support at a lower cost, ultimately generating a higher level of social capital. Therefore, it can be said that the satisfaction of Facebook users has a positive impact on the social capital.

Echoing with the existing literature on SNS and social capital (Ellison et al., 2007; Phua \& Jin, 2011; Raza et al., 2016), the current study prove that use intention has significant positive influence on bridging and bonding social capital. Relationship maintenances, for instance congratulating others, empathizing, cooperating, and helping each other, lead to bridging and bonding social capital. Therefore, this suggests that behavioural intentions (e.g., user satisfaction and continuance use intention) are the best predictors of social capital. Satisfied users tend to have a positive attitude toward social capital. 


\section{Theoretical Implications}

Facebook is not only a communication platform, but an unnatural structural equivalent of social collaboration that offers users with social capital. Users transfer their social capital to the internet and digitalize their lives against the time and space constraints by joining Facebook. The results of this research can assist SNS studies by offering important strategic guidelines and instructions. Concerning the connection between the virtual and offline world, this study offers some points worth understanding how people think about service quality and how they have achieved social capital through the use of SNS. The multidimensional service quality (outcome quality, environment quality, and interaction quality) is verified and it is suggested that outcome and environment qualities are the finest forecasters of SNS usage intent and satisfaction. Thus, by proposing that service quality dimensions are inevitable phenomenon in using SNS, highlighting the tangible evidence, intangible valence and punctuality of service delivery. It is also stressing that the context of service delivery, equipment quality, interface design, visual design, system reliability, navigation, and connection qualities are of significant importance in the context. Additionally, this study proves the different functional mechanism of the effect of use intention and satisfaction on social capital. Persons would not inevitably receive social capital, or feel interactively linked to each other only because of Facebook. Fairly, the service quality dimensions can form their understanding of their social network on Facebook. For instance, the individual will receive support from SNS in the form of networking, esteem, emotional, informational and many other ways, if they find SNS as a reciprocally beneficial platform. Besides, outcomes that involve information, value, interface design, stable network are further likely to be communicative moods on Facebook and then influence bridges and establish relationships. Therefore, the results of this research with aforementioned precise discussions offer a comprehensive contribution to SNS literatures.

\section{Limitations and Future Research Guidelines}

Despite the important contributions, this study has few limitations like any other studies. One of the important facts that this study examines hypothetical relationships based on a single SNS, thus results might not be the same for other SNSs. Because there may be differences in how users meet their expectations in different SNSs, future research could test the model with different SNSs. In addition, since the samples were collected from one country only, the results may not be representative of other countries properly. Therefore, future researches might benefit from using cross-country samples. Finally, we intentionally hypothesized the study model for simplicity and some constraints, while future research could be extended to include some other variables (e.g. subjective norms, offline social capital, or stickiness). Further research may also adopt other longitudinal methods to arrive at better understandings. 


\section{Practical Implications for Asian Business}

Our study finding would be simulated in improving marketing approaches and themes corresponding to user preferences. Hence, output of this study should inspire SNS managers or developers to incorporate this theory, which could be expose to users' psychosomatic traits and improve social capital. These results would stimulate the origination of strategies that will enable effective marketing functions through SNSs and attract users who embrace this site. Our study prioritizes outcome and environment qualities, and practitioners must pay attention to the information displayed and crucial features of Facebook. Therefore, SNS managers should focus intensively on what users actually get from using SNS and in what atmosphere. For instance, managers need to filter out information that is really useful to general users or they may provide target-based information for a particular user group or region. In addition, since there are thousands of SNS already in market, forced to be competitive, therefore managers should incorporate incredible web-design with increased security and privacy. Given the importance of use intention and user's satisfaction, administrators or practitioners should continually incorporate and improve beneficial functions or various value-added activities so that users can meet, build trust, and generate social capital in the virtual world. For instance, SNS can provide group-based video conferencing with wider user access, which may be helpful to building mutual trust and a beneficial relationship among users. The findings could also be useful for the study directed on social network marketing, as it should help managers to implement effective social marketing strategies by giving them important recommendations.

Moreover, our study presents a new association between the multidimensional service quality and the social capital theory on the use of famous SNS Facebook. The results of the study provide insight into how multidimensional service quality is driving user satisfaction and use intention, ultimately affecting social capital acquired from Facebook. These findings are applicable in the Asian business context as these countries show almost similar consumption behaviour. Nowadays, almost every business venture use at least one SNS to promote their product or services, and SNSs users logged in to their SNS page observe other people's comments, make comments, remarks quality and even recommend that product/services. SNSs offers business ventures efficient cost reduction in advertising, reaching billions of people at, strategizing according to the customer choices and so on. Most importantly, SNSs build excellent bridges to people who are geographically far away. For instance, business can reach users across the country and promote their product/services to them. Businesses can provide classified information or messages to culturally, religiously, ethnically different people. Even businesses can have access to some classified information generated by SNSs user group, which will help them fulfil need-base expectations of the customer. Thereby, SNSs platform functions as an important alternative to electronic commerce, and Asian companies should grab this extremely flourishing platform.

Since the technological advancement changed our lives and extensive internet access makes the universe as short as a global village. Anyone wishing to get in touch with 
foreigners is an easy step in this growing number of internet users. As internet surfers increase, SNSs users also increase at a similar rate, which inevitably increases SNSs commerce. In particular, our study is based on one of the emerging economic countries in Asia, therefore, the theoretical and managerial contributions offered are highly regarded as applicable in other Asian countries. For instance, our study shows a noteworthy influence of service quality dimensions of SNS on behavioural intentions of users that will be tracked in Asian companies with a view to achieve higher customer satisfaction and a longer relationship with them. In addition, practitioners are suggested to provide a pleasant environment where customers can share their feelings, show sympathy to their partners, a reciprocally beneficial environment, a problem-solving atmosphere and many other benefits thereby customer can rely to the recommendation provided and make a purchase decision.

\section{References}

Anderson, J. C., \& Gerbing, D. W., (1988), "Structural equation modelling in practice: A review and recommended two-step approach", Psychological Bulletin, vol. 103, no. 3, pp. 411-423.

Bakshy, E., Rosenn, I., Marlow, C., \& Adamic, L., (2012), "The role of social networks in information diffusion", Paper presented at the World Wide Web conference, Lyon, France.

Bano, S., Cisheng, W., Khan, A. N., \& Khan, N. A., (2019), "WhatsApp use and student's psychological well-being: Role of social capital and social integration", Children and Youth Services Review, vol. 103, pp. 200-208.

Bourdieu, P., (1986), The forms of capital, Greenwood, New York.

Brady, M. K., \& Cronin, J., (2001), "Some new thoughts on conceptualizing perceived service quality: A hierarchical approach", Journal of Marketing, vol. 65, no. 3, pp. 3449.

Browne, M. W., \& Cudeck, R., (1993), Alternative ways of assessing model fit, Sage Publications, California.

Coleman, J. S., (1988), "Social capital in the creation of human capital", The American Journal of Sociology, vol. 94, pp. 95-120.

Cronin, J. J., \& Taylor, S. A., (1992), "Measuring service quality: A re-examination and extension", Journal of Marketing, vol. 56, no. 3, pp. 55-68.

Doll, J. W., Xia, W., \& Torkzadeh, G., (1994), "A confirmatory factor analysis of the enduser computing satisfaction instrument", MIS Quarterly, vol. 18, no. 4, pp. 453-461.

Dyke, V., Kappelman, T. P., \& Prybutok, V. R., (1997), "Measuring information system service quality: Concerns on the use of the SERVQUAL questionnaire", MIS Quarterly, vol. 21, no. 2, pp. 195-208.

Ellison, N. B., Steinfield, C., \& Lampe, C., (2007), "The benefits of Facebook "friends:" Social capital and college students' use of online knowledge sharing among tourists via social media social network sites", Journal of Computer-Mediated Communication, vol. 12, pp. 1143-1168.

Ellison, N. B., Vitak, J., Gray, R., \& Lampe, C., (2014), "Cultivating social resources on social network sites: Facebook relationship maintenance behaviours and their role in social capital processes", Journal of Computer-Mediated Communication, vol. 19, no. 4, pp. 855-870.

Ellison, N. B., Gray, R., Lampe, C., \& Fiore, A. T., (2014b), "Social capital and resource request on Facebook", New Media \& Society, vol. 16, no. 7, pp. 1104-1121.

Gronroos, C. A., (1984), "Service quality model and its marketing implications", European Journal of Marketing, vol. 18, no. 4, pp. 36-44. 
Hair, J. F., Black, W. C., Babin, B. J., Anderson, R. E., \& Tatham, R. L., (2010), Multivariate data analysis, Pearson Education, New Jersey.

High, A. C., \& Buehler, E. M., (2019), "Receiving supportive communication from Facebook friends: A model of social ties and supportive communication in social network sites", Journal of Social and Personal Relationships, vol. 36, no. 3, pp. 719-740.

Hossain, M. A., \& Kim, M., (2018), "Does multidimensional service quality generate sustainable use intention for Facebook?", Sustainability, vol. 10, p. 2283.

Hossain, M. A., \& Kim, M., (2020), "A comprehensive study on social commerce in social networking sites", Sage Open, pp. 1-13.

Kuo, Y. F., Wu, C. M., \& Deng, W. J., (2009), "The relationships among service quality, customer satisfaction, and post-purchase intention in mobile value-added services", Computers in Human Behaviour, vol. 25, no. 4, pp. 887-896.

Lien, C. H., Cao, Y., \& Zhou, X., (2017), "Service quality, satisfaction, stickiness and usage intentions: An exploratory evaluation in the context of WeChat services", Computers in Human Behaviour, vol. 68, pp. 403-410.

Lu, Y., Zhang, L., \& Wang, B., (2009), "A multidimensional and hierarchical model of mobile service quality", Electronic Commerce Research and Applications, vol. 8, no. 5, pp. 228-240.

Parasuraman, A., Zeithaml, V. A., \& Berry, L. L., (1985), "A conceptual model of service quality and its implications for future research", Journal of Marketing, vol. 49, no. 3, pp. 41-50.

Phua, J., \& Jin, S. A. A., (2011), "Finding a home away from home: The use of social networking sites by Asia-Pacific students in the United States for bridging and bonding social capital", Asian Journal of Communication, vol. 21, no. 5, pp. 504-519.

Phua, J., Jin, S. V., \& Kim, J., (2017), "Uses and gratifications of social networking sites for bridging and bonding social capital: A comparison of Facebook, Twitter, Instagram, and Snapchat", Computers in Human Behaviour, vol. 72, pp. 115-122.

Podsakoff, P. M., MacKenzie, S. B., Lee, J. Y., \& Podsakoff, N. P., (2003), "Common method biases in behavioural research: A critical review of the literature and recommended remedies", Journal of Applied Psychology, vol. 88, no. 5, pp. 879-903.

Putnam, R. D., (2000), Bowling alone: The collapse and revival of American community, Simon and Schuster, New York.

Raza, S. A., Qazi, W., \& Umer, A., (2016), "Facebook is a source of social capital building among university students: Evidence from a developing country", Journal of Educational Computing Research, pp. 1-28.

Su, C. C., \& Chan, N. K., (2017). "Predicting social capital on Facebook: The implications of use intensity, perceived content desirability, and Facebook-enabled communication practices", Computers in Human Behaviour, vol. 72, pp. 259-268.

Tobin, S. J., Chant, G., \& Clay, R., (2020), "Interpersonal goals as predictors of Facebook use, social capital, and envy", Cyberpsychology, Behaviour, and Social Networking, vol. 23, no. 4, pp. 257-263.

Valenzuela, S., Park, N., \& Kee, K. F., (2009), "Is there social capital in a social network site? Facebook use and college students' life satisfaction, trust, and participation", Journal of Computer-Mediated Communication, pp. 875-901.

Williams, D., (2006), "On and off the 'net: Scales for social capital in an online era", Journal of Computer-Mediated Communication, vol. 11, no. 2, pp. 593-628.

Williams, J. R., (2019), "The use of online social networking sites to nurture and cultivate bonding social capital: A systematic review of the literature from 1997 to 2018 ", New Media \& Society, vol. 21, no. 11-12, pp. 2710-2729.

Zhang, M., Guo, L., Hu, M., \& Liu, W., (2016), "Influence of customer engagement with company social networks on stickiness: Mediating effect of customer value creation", International Journal of Information Management, pp. 1-12. 
Zhao, L., Lu, Y., Zhang, L., \& Chau, P. Y. K., (2012), “Assessing the effects of service quality and justice on customer satisfaction and the continuance intention of mobile value-added services: An empirical test of a multidimensional model", Decision Support System, vol. 52, no. 3, pp. 645-656. 